\title{
SIROMAŠTVO I SOCIJALNA ISKLJUČENOST U MEDIJSKOM DISKURSU RADIO-STANICA SRBIJE ${ }^{1}$
}

Kvantitativno-kvalitativna analiza medijskog diskursa o siromaštvu i socijalnoj isključenosti obuhvatila je korpus od 27 centralnih radijskih informativnih emisija koje su emitovane na četiri radio-stanice: republičkom i pokrajinskom javnom servisu, komercijalnom regionalnom mediju, kao i radio-stanici koje su i dalje u nadležnosti lokalne samouprave. Ukupno je uočeno 37 tematskih priloga (oko 9 priloga u proseku po stanici) što je daleko manje od prethodnog istraživanja 2010, kada je uočeno 84 priloga u emisijama sedam radio- stanica (12 priloga u proseku po stanici).

Analiza je pokazala da su kao najčešće identifikovane socijalno isključene grupe: svi siromašni građani, žene, deca i radnici i studenti. U ulozi subjekta najčešće se javljaju državni organi i sindikati, dok se glas ,,socijalno ugroženih” gotovo i ne čuje.

Ključne reči: radio-stanice, javni servis, komercijalni mediji, informativna emisija, izveštavanje, siromaštvo, socijalna isključenost.

\section{UVODNE NAPOMENE}

Populacija najsiromašnijih zemalja sveta raste gotovo četiri puta brže od stanovništva bogatih država. Prema podacima iz istraživanja Službe za analitičku informatiku Međunarodne organizacije kreditora (WOC) za 2011, ${ }^{2}$ oko pet milijardi (72\%) ljudi na planeti živi u zemljama sa prosečnim prihodima, u zemljama sa visokim prihodima živi 1,1 milijarda (16\%) stanovnika, a oko 800 miliona (12\%)

$1 \quad$ Ovaj rad pripremljen je u okviru Regionalnog programa podrške istraživanjima u oblasti društvenih istraživanja na Zapadnom Balkanu (RRPP), koji vodi Univerzitet u Frajburgu, uz finansijsku podršku Agencije za razvoj i saradnju Švajcarske (SDC). Mišljenja izneta u ovom radu su mišljenja autora i ne predstavljaju nužno mišljenja SDC ni Univerziteta u Frajburgu.

2 Rezultati istraživanja dostupni na srpskom jeziku na: http://www.tanjug.rs/novosti/31278/brojsiromasnih-raste-cetiri-puta-brze-od-bogatih.htm (posećeno 10.05.2012). 
ljudi živi u najsiromašnijim zemaljama sveta. Broj siromašnih građana Srbije, koji ne mogu da zadovolje osnovne životne potrebe, je u konstantnnom porastu, a ispod granice siromaštva živi blizu 700.000 ljudi.

U Prvom nacionalnom izveštaju o socijalnom uključivanju $i$ smanjenju siromaštva u Republici Srbiji za period 2008-2010, ${ }^{3}$ koji je u martu 2011. usvojila Vlada Republike Srbije navodi se da su na porast siromaštva uticali svetska ekonomska kriza i loša situacija na tržištu rada. Stopa apsolutnog siromaštva povećana je na 6,9\% u 2009, odnsno na 9,2\% u 2010. Republika Srbija, tokom procesa približavanja Evropskoj uniji, između ostalog, bila je u obavezi da usvoji Strategiju sa smanjenje siromaštva $(\mathrm{SSS})^{4}$. Ta strategija predstavlja srednjoročni razvojni okvir usmeren na smanjenje ključnih oblika siromaštva u Srbiji. ${ }^{5}$ SSS deklarativno predviđa privredni razvoj, sprečavanje pojave novog siromaštva i brigu o tradicionalno siromašnim grupama (deca, stari, osobe sa invaliditetom, izbeglice i interno raseljena lica, Romi, ruralno siromašno stanovništvo i neobrazovani, nazaposleni).

Pored državne strategije, mediji takođe imaju vrlo važnu i odgovornu ulogu, ako ne u direktnom sprečavanju ili smanjenju siromaštva, onda ukazivanjem na probleme koje imaju socijalno ugrožene grupe, kako bi javnost bila informisana o tome i eventualno preduzela nake korake za rešavanje problema.

\section{DEFINISANJE PREDMETA ISTRAŽIVANJA}

Cilj ovog rada jeste da ukaže na koji način mediji izveštavaju o siromaštvu i socijalno isključenim grupama, ali i da na osnovu rezultata prethodnog istraživanja ${ }^{6}$ kroz kritičku analizu medijskog diskursa pokaže ima li promena u pristupu ovom društvenom fenomenu.

Siromaštvo se ogleda kroz „,nedostatak prihoda i sredstava dovoljnih da se osigura održiva egzistencija, glad i neuhranjenost, slabo zdravlje, ograničena ili nikakva mogućnost obrazovanja, povećana smrtnost od bolesti, beskućništvo

3 Kompletan izveštaj Vlade Republike Srbije dostupan je u PDF formatu na: http://www.inkluzija. gov.rs/wp-content/uploads/2011/03/Prvi-nacionalni-izvestaj-o-socijalnom-ukljucivanju-ismanjenju-siromastva1.pdf (posećeno 10.05.2012).

4 Dostupno na sajtu: http://www.prsp.gov.rs/strateski.jsp (posećeno: 11.04.2012).

5 Detaljnije na sajtu SSS http://www.prsp.gov.rs/strateski.jsp (posećeno: 14.04.2012).

6 Prethodno istraživanja obavljeno je 2010, a rezultati su predstavljeni u zborniku Media Discourse of Poverty and Social Exclusion, posebno za radio-stanice u radu Pralica 2011: 77-91. 
i neadekvatni stambeni uslovi, nesigurno okruženje, društvena diskriminacija i izolacija“ (Tomić 2007: 149-150).

Socijalna isključenost ,postala je jedna od najpopularnijih tema društvenih nauka. Neki čak smatraju da je socijalna isključenost 'glavni društveni problem našeg vremena' koji potiskuje stare ustaljene pristupe, posebno siromaštva i marginalizacije“ (Šućur 2006:10). Socijalna isključenost jeste širi pojam u odnosu na siromaštvo. „To je proces kroz koji se određeni pojedinci ili grupe potiskuju na rub društva“ ( Kušljugić, Prohić 2009:7).

Diskurs posmatram kao veću jedinicu od rečenice (govorne ili pisane poruke) koja je ostvarena između sagovornika u nekom kontekstu (Savić 1993: 29-33). Diskurs obuhvata i pisanu komunikaciju, čak i pisanu interakciju, s tim da čitalac, odnosno slušalac u ovom istraživanju, i autor nisu u interakciji licem u lice (Van Dijk 1998: 2-3). Medijski diskurs jeste širok pojam koji može da se odnosi na sveukupnu stvarnost koja je predstvljena kroz štampane i elektronske medije (O' Keeffe 2006: 1).

Radio-stanice, čije informativne emisije u ovom radu analiziram, reprezentuju javni servisi, medijske kuće koje su u javnom vlasništvu u Srbiji. U ovom istraživanju to su Radio-televizija Srbije - Radio Beograd i Radio-televizija Vojvodine - Radio Novi Sad. Od komercijalnih medija, koji su u vlasništvu privatnih lica ili kompanija - Novinska agencija Beta - regionalni Radio Sto plus iz Novog Pazara i medij lokalne zajednice ${ }^{7}$, koji je u vlasništvu lokalne samouprave - Grada Zrenjanina - regionalni Radio Zrenjanin.

\section{METODOLOGIJA ISTRAŽIVANJA}

Prilikom analize informativnih emisija radio-stanica korišten je metod kvantitativno-kvalitativne analize medijskog diskursa. Analiza medijskog diskursa izučava društvo i proučava koje vrste interakcija tekst uspostavlja između ljudi i sveta i između moćnih (vlasti, većine) i onih koji to nisu (manjine -pripadnika socijalno isključenih grupa) (prema Matheson 2005: 1-3).

$7 \quad$ Radio lokalne zajednice, prema Zakonu o radiodifuziji (član 96), jeste onaj medij čiji je osnivač skupština opštine ili grada. Prečišćen tekst: Službeni glasnik Republike Srbije, br . 42/2002, 97/2004, 76/2005, 79/2005 - dr. zakon, 62/2006, 85/2006 i 86/2006 - ispr.). Ovi takozvani opštinski ili gradski mediji trebalo je da, po Zakonu, budu privatizovani do kraja 2008, što se nije dogodilo. 
Za potrebe ovog istraživanja kreiran je poseban kodni list koji je obuhvatio čak 30 kategorija, od kojih će u radu biti prikazane samo one u kojima su dobijeni relevatni podaci.

\section{KORPUS I JEDINICA ANALIZE}

Istraživački korpus predstavlja preslušanih 605 minuta materijala, odnosno 27 centralnih informativnih emisija četiri radio-stanice, koje su ciljano snimane za određene datume u 2011. i to $14,16,17,19,22,25$. i 27. oktobra. ${ }^{8}$ Namera je bila da se datumima obuhvate Svetski dan hrane (16. oktobar) i Svetski dan borbe protiv siromaštva (17. oktobar), kao i dani neposredno oko tih datuma.

Jedinica analize jeste informativni prilog unutar emisije koji sadrži govor voditelja/novinara, odnosno tonski snimak sa terena ili glas sagovornika. Istraživanjem je, dakle, obuhvaćeno ukupno 37 priloga u kojima su novinari izveštavali o siromaštvu i socijalnoj isključenosti.

\section{ANALIZA I REZULTATI}

Analiza informativnih priloga u glavnim informativnim emisijama četriri radio-stanice pokazala je da postoji interesovanje medija za temu siromaštva i socijalne isključenosti, što je i bilo očekivano, budući da je Srbija zemlja u tranziciji ${ }^{9}$, a kako su i sama istraživanja javnog mnjenja pokazala (prema Pralica 2011: 78-79), ova tema je, čini se, bar kada je Srbija u pitanju, svevremena. Za sedam posmatranih dana o aktuelnoj temi najviše su izveštavali novinari republičkog (12 puta) i pokrajinskog javnog servisa (11 puta), Radio Zrenjanin (osam puta), a najmanje Radio Sto plus (šest puta). Broj tematskih priloga po radio-stanicama dat je u tabeli 1. U odnosu na prethodno istraživanje (Pralica 2011: 82), uočen je trend smanjena broja tematskih priloga i to kod Radio Beograda za 33\%, Radio Novog Sada za 39\% i Radio Zrenjanina za 50\%. Ovaj podatak može se tumačiti realno manjim brojem aktuelnih događaja u vezi sa protestima i štrajkovima radnika u odnosu na 2010,

$8 \quad$ Radio Beograd, Radio Novi Sad i Radio Sto plus imali su tokom posmatranog perioda po sedam emisija, a Radio Zrenjanin šest. Broj informativnih emisija zavisio je od toga koliko ih radiostanica ima tokom sedmice.

9 Termin kojim se označavaju zemlje koje prelaze iz socijalizma u kapitalizam. Jedan od najvećih problema tranzicije jeste nezaposlenost. 
odnosno smanjanim interesovanjem novinara za ovu temu.

\begin{tabular}{|c|c|c|c|}
\hline radio stanica & $\begin{array}{c}\text { broj snimljenih } \\
\text { emisija }\end{array}$ & $\begin{array}{c}\text { broj tematskih } \\
\text { informativnih } \\
\text { priloga }\end{array}$ & $\begin{array}{c}\text { prosečno priloga } \\
\text { po emisiji }\end{array}$ \\
\hline \hline Radio Beograd 1 & 7 & 12 & 1,7 \\
\hline Radio Novi Sad 1 & 7 & 11 & 1,6 \\
\hline $\begin{array}{c}\text { Radio Sto plus Novi } \\
\text { Pazar }\end{array}$ & 7 & 6 & 1,3 \\
\hline Radio Zrenjanin & 6 & 8 & 0,8 \\
\hline
\end{tabular}

Tabela br. 1 Odnos radio-stanica i tematskih priloga

\section{1. ŽANR}

Kvantitativno-kvalitativna analiza žanra u informativnim radijskim emisijama, u vezi sa tematskim prilozima, pokazala je dominaciju trivijalnijih žanrova 57\% (vest, izveštaj), a odsustvo kompleksnijih žanrova, poput intervjua. Ono što je različito u odnosu na prethodno istraživanje jeste povećanje broja radio-paketa sa $20 \%$ na $39 \%$, i to zahvaljujući angažovanju novinara javnih servisa koji očito više nego ranije neguju ovaj žanr. Posmatrajući ukupno, radio-stanice su o siromaštvu i socijalnoj isključenosti najčešće informisale slušaoce kroz žanr izveštaja i radiopaketa (po 39\%) zatim kroz vesti (18\%), i kroz samo jednu reportažu. Pristup nekoj temi kroz složenije žanrove poput radio-paketa ili reportaže sigurno ima daleko više uticaja na slušalačku publiku od kratke forme vesti ili nešto dužeg izveštaja.

I pored toga što je radio-paket veoma dobro odabran žanr ukoliko imamo veći broj sagovornika, postoje primeri kada je bolje umesto tog žanra napraviti reportažu. Primer za to je priča o životu Roma u novosadskom naselju Bangladeš (Radio Novi $S a d, 19.10 .2011)$, kada se u prilogu kao sagovornici pojavljuju gradonačelnik i lokalni Romi. Ovaj prilog bio bi daleko primereniji temi kada bi novinar napravio reportažu, zato što bi sa daleko više detalja reportaža mogla da dočara život u tom naselju. $\mathrm{U}$ ovom istraživanju ističem jedinu reportažu koju je napravila novinarka Radio Beograda Ana Tomašević (Radio Beograd,16.10.2011) . Budući da je novinarka 
u potpunosti uspela da na veoma kreativan način, koristeći prednosti imaginacije radija, prikaže u tri minuta život majke i ćerke u Prizrenu, smatrao sam da je važno da kroz sinopsis priče predstavim kako se jedna tema razvija - od uredničke najave pa do kraja priloga.

- Najava reportaže: Od više od 10.000 Srba koliko ih je u Prizrenu bilo do 1999, danas u gradu živi jedva njih 30, Među njima je i jedno dete, šestogodišnja Milica Đorđević. Njena majka Evica voli Prizren i život u njemu. Sve što želi je da život bude malo lepši, lakši i slobodniji. Sa Milicom i njenom mamom bila je i naša Ana Tomašević

- Reportaža: (u pozadini etno pesma; devojčica nabraja slova azbuke, a novinarka je pita gde je slovo P).

Novinarka: $P$ - kao Prizren, $\check{Z}$ - kao život. Za šestogodišnju Milicu Đorđević i mamu Evicu te dve reči znače sve. Prizren je glavni razlog što u njemu ostaju, a život normalan, pravi, ono je za čime žude.

Majka: Ja se trudim da bude...sve normalno, onako. Okolnosti su takve kakve su, al' ja se borim. Ove nesreće valjda su nas očvrsle...Teško mi je to što ja i Milica same ne možemo da iziđemo. Znači, sloboda kretanja.

Novinarka: Tako je od martovskog pogroma 2004.

Majka: 17. marta su palili srpske kuće, isterivali ljude iz svojih kuća.., a šta je isto najgore - palili su i naše svetinje. Ja sam sve to posmatrala sa prozora...

Novinarka: Čak i kad je bilo najteže, kad su same ostavljene početkom marta 2004, prosto im je nacrtano.

Majka: Ja sam imala na vratima plakat gde je na nemačkom, albanskom i srpskom pisalo da ovaj stan i lica koje su u njemu, imovinu štiti vojna policija i potpis. Ja sam odmah shvatila da smo ostavljeni.

Novinarka: Mala Milica, jedino srpsko dete u Prizrenu, raste s tim teretom.

Majka: Samo traži da joj kupim igračku Ben - Tena, , ja pitam što ne nekog drugo iz crtanog, a ona kaže zato što se bori za pravdu. I sve pobeđuje. 
Novinarka: Pomaže Ben Ten, ali više komšija deda Ada, musliman koji je primio hrišćanstvo zbog lepote (Bogorodice) Ljeviške i Milicinih toplih očiju. Bez njega ne mrdaju iz stana. S njim do prodavnice, do crkve na liturgiju i jednom mesečno po socijalnu pomoć od 50 evra. Toliko dobija porodica Đorđević od Vlade Srbije i od toga živi. Milica nema drugare. Ne ide u vrtić. Ne igra se u parkiću. U gradu, njen se jezik ne čuje. Osim u Bogosloviji, 10 minuta prečicom od stana ili malo dalje u crkvi. Zato oskrnavljene crkve i manastire u gradu čuvaju bodljikava žica $i$ policija. Ljudi, kao Evica, snalaze se sami. Vraća u stvarnost Spasa Andrijević, opštinski službenik za povratak.

Službenik: Raspolažem sa ciframa da je grad Prizren do '99. brojao negde između 10 i 12 hiljada Srba. 2005. taj broj je bio 314, 315 i danas, kao što sam rekao 185.

Novinarka: A ciframa prkosi samo nada.

Majka: (u pozadini se tiho čuje erno pesma) Nadamo se boljem životu. Povratku naših ljudi. To je moja želja i nada da se naši ljudi vrate, da nisu zaboravili svoj rodni grad, svoje Kosovo i Metohiju.

Novinarka: Evici i Milici samo to i treba. P-kao Prizren i $\check{Z}-$ kao život.

Novinarka je ovu priču mogla da prenese informativno, da razgovara sa majkom i ćerkom i nabroji činjenice u vezi sa teškim životom koje imaju u Prizrenu. Ipak, odlučila se za žanr reportaže, što je bilo sasvim opravdano i u skladu sa temom.

\subsection{FORMA}

Aktuelni tonski snimak subjekta (osobe čiji se glas čuje u radijskom prilogu) u ukupnom uzorku zastupljen je sa $76 \%$, što je veoma dobro, budući da je glas na radiju nešto što informaciju čini verodostojnijom i originalnijom, u odnosu na to kada spiker čita agencijske vesti ili interpretira nečije reči. Sve medijske kuće, čije su informativne emisije analizirane, prema rezultatima istraživanja, čini se, svesne su važnosti forme priloga, te su se novinari podjednako trudili da dođu do snimka/ glasa sagovornika u odnosu na sam tekst koji čita spiker. U ovoj kategoriji, u odnosu na prethodno istraživanje, zabeležen je napredak i to za oko $20 \%$ u korist autentičnih snimaka sagovornika, što je vredno pomena. 


\subsection{POVOD IZVEŠTAVANJA}

I u ovoj kategoriji, novinari su u odnosu na pre godinu dana napravili pomak. Povećali su svoj lični angažman i pristup temi kroz medijsku inicijativu za 16\%, izveštavanje sa aktuelnih događaja za $6 \%$, dok je u potpunosti izostalo izveštavanje sa konferencija za novinare, odnosno presododogađaja,što se smatra neinventivnim angažovanjem novinara. Kako su konferencije za novinare situacije kada onaj ko ih saziva želi da nešto saopšti novinarima, odnosno poziva ih da samo pasivno prenesu ono što su organizatori pripremili, izostanak ovakve perspektive povoda izveštavanja kod radijskih novinara (spram 21\% 2010) treba pozdraviti.

\subsection{SOCIJALNO ISKLJUČENE GRUPE}

Kada je u pitanju kategorija identifikacija socijalno isključenih grupa, analiza je pokazala da su najbrojniji među ovom grupom radnici $(22 \%)^{10}$ i svi siromašni građani (17\%). Jednako (11\%) su zastupljeni stari, žene i deca i nešto manje (9\%) studenti. Daleko manje bili su vidljivi: izbeglice (4\%), kao i beskućnici i Romi (po 2\%). Ovi podaci odražavaju izveštavanje medija tokom oktobra 2011. kada je u Srbiji bilo protesta radinika usled propalih privatizacija u nekada državnim preduzećima, štrajkova radnika zbog neisplaćenih zarada, kao i protesta studenata u Beogradu i Novom Sadu koji su tražili bolje uslove za studiranje. O starima, ženama i deci najviše se govorilo o kontekstu toga koliko država ili lokalna zajednica, kroz različite projekte, pomaže ove kategorije stanovništva (grafikon 1). 


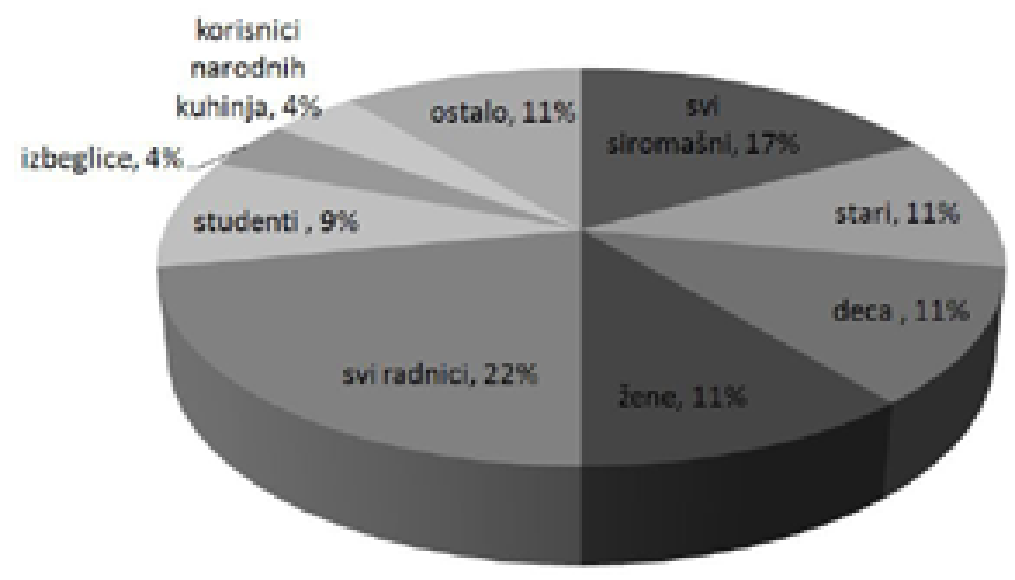

Grafikon 1: Identifikacija socijalno isključenih grupa u radio-stanicama u Srbiji

\subsection{SUBJEKTI I OBJEKTI}

Rezultati koji su dobijeni nakon analize kategorije subjekat - kao osobe čiji se glas čuje i koja ima rezervisano vreme da nešto kaže na radiju, pokazali su da su mediji najviše prostora za iskazivanje stavova ustupili vlastima ${ }^{11}(25 \%)$ i nevladinim organizacijama i sindikatima (zajedno 18\%), kao i ekspertima (10\%). U odnosu na prethodno istraživanje, novinari su za $9 \%$ manje navodili vlast, dok su ovaj put, opet u odnosu na prethodno istraživaja, kada ih nije bilo, eksperti prisutni u određenoj meri. Sve ostale kategorije imaju oko 5\% i manje og toga, tako da ti podaci nisu reprezentativni za analizu. Međutim, i te podakje je važno napomenuti pošto su mediji mogli daleko više da ustupe vremena socijalno ugroženim grupama, socijalnim ustanovama, ali i i samim građanima u vidu anketa što je govoto u potpunosti izostalo. ${ }^{12}$ Time su mediji (ne)svesno napravili $d v o s t r u k u$ diskriminaciju socijalno isključenih grupa ne ustupajući im dovoljno (ili uopšte) vremena da iznesu svoje mišelje, odnosno da lično govore o svojim problemima. Na primer, žene se kao subjekti javljaju u svega $3 \%$ primera, dok su deca, stari etničke manjine i radnici još

11 Republičke vlasti 18\%, lokalne vlasti 5\% i pokrajinske vlasti $2 \%$.

12 NVO i sindikati $18 \%$, ekspeti $10 \%$, Centar za socijalni rad 5\% i tako dalje. 
manje zastupljeni (2\%).

„Socijalnu isključenost treba razumeti kao trajnu, višestruko uslovljenu i višedimenzionalnu uskraćenost pojedinca“ (Matković, Štulhofer 2006: 26-29). Nažalost, posmatrani mediji učinili su da predstavnici socijalno isključenih grupa gotovo da nemaju pristup etru. ${ }^{13} \mathrm{O}$ socijalno isključenima (kao objektima) najčešće neko govori, dok se njihov glas vrlo retko čuje. Pa i tada mediji najčešće, suprotno očekivanjima istraživača, markiraju vlast (republičku i pokrajinsku) (26\%), a daleko manje one kojih se ti problemi direktno tiču, kao na primer žene i opštu populaciju (po 10\%), decu, stare i studente (po 8\%). Ostalih kategorija stanovništva ima između $4 \%$ i $2 \%$.

Za razliku od direktne diskriminacije, kada je „različitost određene grupe ljudi osnovni razlog za nejednako postupanje“, indirektna diskriminacija je „'skrivena' iza mera, kriterijuma i procedura koje su naizgled neutralne, ali rezultiraju nejednakim položajem određenih grupa ili osoba“. Tako striktna primena „načela neutralnosti može dodatno učvrstiti posledice dugotrajne diskriminacije“" ( Papa 2006:48).

\subsection{VREDNOSNI ODNOS AUTORA PREMA TEMI PRILOGA}

Analiza je pokazala da gotovo svi novinari Radio Beograda, Radio Novog Sada, Radio Zrenjanina i Radija Sto plus imaju neutralan vrednosni odnos prema temi o kojoj izveštavaju. Tako su rezultati pokazali da novinari četri pomenute redakcije objektivno prikazuju posmatrane teme. Ovaj podatak mogao bi biti pohvalan da je u pitanju klasični informativni program gde dominiraju isključivo političke teme. Međutim, u socijalnim temema, kao što je siromaštvo gde se profesionalno očekuje od novinara da ima svoj stav u vezi sa nekim problemom, pa čak da kritikuje odnos države ili pohvali rešavanje nekog problema, mišljenje novinara potpuno izostaje, te se novinar, na neki način, stavlja po strani bilo da je u pitanju nešto dobro ili loše. Izuzetak u ovom istraživanju jeste reportaža novinarke Radio Beograda o životu majke i ćerke u Prizrenu, sa kojima novinarka saoseća. Sa druge strane, kritičkih (negativnih) stavova novinara uopšte nema, dok je prilikom prethodnog istraživanja zabeležen samo jedan negativni stav, što je takođe bilo nedovoljno s obzirom na temu i sagovornike priloga. 


\section{ZAKLJUČNE NAPOMENE}

Kvantitativno-kvalitativna analiza medijskog diskursa o siromaštvu i socijalnoj isključenosti koja je obuhvatila korpus od 27 centralnih radijskih informativnih emisija, u okviru kojih je markirano 37 tematskih priloga, pokazala je u odnosu na prethodno istraživanje kvantitaivno manje tematskih priloga po emisiji, ali kvalitativno delimično poboljšanje žanrovske strukture i forme priloga. $\mathrm{U}$ poslednjem istraživanju, kao jedan od češće korištenih žanrova izdvaja se radio paket, a broj tonskih inserata daleko je veći nego ranije.

Pomak napred učinjen je i u kategoriji povod izveštavanja s obzirom na to da u ovom istraživanju nije bilo uočenog izveštavanja novinara sa pseudodogađaja, već isključivo sa aktuelnih događaja ili kroz pojačan lični angažman - medijsku inicijativu.

Sa druge strane, u kategorijama subjekata i objekata ponovo (ne)opravdano dominiraju predstavnici vlasti, dok se se glas socijalno ugroženih gotovo i ne čuje. Skoro stoprocentni neutralan odnos novinara prema tematskim prilozima ne može a priori značiti da je neutralno novinarstvo najbolje novinarstvo, s obzirom na to da je reč o vrlo osetljivoj i ranjivoj kategoriji ljudi koji se pominju u prilozima. Njima radijski novinari, kako je pokazalo i ovo istraživanje, ponovo nisu dali šansu da govore.

Kvalitativna promena $\mathrm{u}$ domenu strukture $\mathrm{i}$ forme priloga jeste dobra, ali nije dovoljna za sveobuhvatno i kvalitetno informisanje slušalaca i slušateljki o temi koja će, u odnosu na društveno-političke okolnosti, još neko vreme biti među aktuelnijima. Samim tim veća je i odgovornost novinara prema javnosti, jer novinar - kritičar i istraživač uvek istupa u ime javnosti i brani stavove javnosti u odnosu na političare i vlast.

\section{LITERATURA}

Kušljugić, Branka; Prohić, Ibrahim (2009). Socijalno isključeni u BiH danas, a sutra? Istaživanje. Tuzla, Banjaluka: Evropska unija, Biro za ljudska prava, Helsinški parlament građana.

Matheson, Donald (2005). Media Discourses - Analysing Media Texts. New 
York: Open University Press.

Matković, Teo; Štulhofer, Aleksandar (2006). Istraživanja socijalne isključenosti - empirijska analiza. Siromaštvo, nezaposlenost i socijalna isključenost (zbornik izvještaja). Zagreb: Program Ujedinjenih naroda za razvoj (UNDP Hrvatska). 26-29.

O'Keeffe, Anne (2006). Investigating Media Discourse. New York: Routledge.

Papa, Jasmina (2006). Diskriminacija - mehanizam socijalnog isključivanja. Siromaštvo, nezaposlenost i socijalna isključenost (zbornik izvještaja). Zagreb: Program Ujedinjenih naroda za razvoj (UNDP Hrvatska). 48-59.

Pralica, Dejan (2011). Analiza medijskog diskursa siromaštva i socijalne isključenosti u radijskim informativnim emisijama javnih servisa, komercijalnih medija i medija lokalnih zajednica. Media Discourse of Poverty and Social Exclusion-zbornik radova. 77-91.

Savić, Svenka (1993). Diskurs analiza. Novi Sad: Univerzitet u Novom Sadu - Filozofski fakultet.

Šućur, Zoran (2006). O pojmu socijalne isključenosti. Siromaštvo, nezaposlenost $i$ socijalna isključenost (zbornik izveštaja). Zagreb: Program Ujedinjenih naroda za razvoj (UNDP Hrvatska). 10-12.

Tomić, Velinka (2007). Siromaštvo i socijalna isključenost - osnovne definicije i indikatori. Sociološka luča I/2. Nikšić. 149-166.

Van Dijk, Teun Adrianus (1998). The Study of Discourse. Discourse as Structure and Process - Discourse Studies: A Multidisciplinary Introduction. London: Sage Publications. Vol. 1: 1-34.

internetski izvori:

Strategija za smanjenjesiromaštva Srbije dostupno na sajtu: http://www.prsp.gov.rs/strateski.jsp (posećeno: 10.05.2012)

http://www.tanjug.rs/novosti/31278/broj-siromasnih-raste-cetiri-puta-brzeod-bogatih.htm (posećeno 10.05.2012).

http://www.inkluzija.gov.rs/wp-content/uploads/2011/03/Prvi-nacionalniizvestaj-o-socijalnom-ukljucivanju-i-smanjenju-siromastva1.pdf (posećeno 10.05.2012). 
http://www.prsp.gov.rs/strateski.jsp (posećeno: 14.04.2012).

Dejan Pralica

POVERTY AND SOCIAL EXCLUSION IN THE MEDIA DISCOURSE OF SERBIAN RADIO STATIONS ${ }^{14}$

\begin{abstract}
Summary
Quantitative and qualitative media discourse analyses of poverty and social exclusion were done on the corpus of 27 radio news programs broadcast on four radio stations: national and provincial public services, a commercial regional medium and a radio station run by a local government.There was a total of 37 packages (on average 9,25 packages per station) which is far less than in the previous research done in 2010 when there was 84 packages on seven radio stations (on average 12 packages per station).

This analysis has shown that most often identified socially excluded groups are: the poor, women, children and workers and students. Government institutions and unions are usually in the role of subject, while the voice of the "socially disadvantaged" is hardly ever heard.
\end{abstract}

Key words: radio stations, public service, commercial media, news program, reporting, poverty, social exclusion

14 Prepared within the framework of the Regional Research Promotion Programme in the Western Balkans (RRPP), which is run by the University of Fribourg upon a mandate of the Swiss Agency for Development and Cooperation, SDC, Federal Department of Foreign Affairs. The views expressed in the paper are those of the authors and do not necessarily represent opinions of the SDC and the University of Fribourg. 